\title{
$\overline{A M} \mid$ SCHOOL OF LAW

Volume 7

Number 3 Oil \& Gas Survey

Article 19

5-12-2021

\section{Solving the Interconnection Problem}

Ralph A. Cantafio

Ralph@fncmlaw.com

Miles C. Nowak

mnowak@fncslaw.com

Follow this and additional works at: https://scholarship.law.tamu.edu/journal-of-property-law

Part of the Oil, Gas, and Mineral Law Commons, and the Property Law and Real Estate Commons

\section{Recommended Citation}

Ralph A. Cantafio \& Miles C. Nowak, Solving the Interconnection Problem, 7 Tex. A\&M J. Prop. L. 526 (2021).

Available at: https://doi.org/10.37419/JPL.V7.I3.19

This Student Article is brought to you for free and open access by Texas A\&M Law Scholarship. It has been accepted for inclusion in Texas A\&M Journal of Property Law by an authorized editor of Texas A\&M Law Scholarship. For more information, please contact aretteen@law.tamu.edu. 


\title{
SOLVING THE INTERCONNECTION PROBLEM
}

\author{
Ralph A. Cantafio, Esq.` and Miles C. Nowak, Esq. ${ }^{\dagger}$
}

\begin{abstract}
The distinct three energy grids as such exist in the United States (the Western Interconnection, the Eastern Interconnection, and the Texas Interconnection or ERCOT) unnecessarily constrain the United States in addressing its future energy needs, as electricity flow between the three grids is very limited. As our country's reliance on traditional nonrenewable energy sources like coal continue to decline and the reliance on renewable energy sources continues to grow, the United States should focus on replacing the existing three-grid system with a national energy grid that will benefit energy companies and consumers, as well as serve our future energy needs. This Article provides both an overview of the current energy system in the United States and evidence in support of a solution-creation of a national energy grid.
\end{abstract}

\section{INTRODUCTION: THE INTERCONNECTION PROBLEM}

As leaders in the energy industry, responsible commentators have an obligation to both raise and discuss problems within the industry and to seek solutions. The significance here is economic, domestic energy self-reliance, and environmental in nature. This Article is an attempt to raise awareness as to one of the great energy issues facing

DOI: https://doi.org/10.37419/JPL.V7.I3.19

†Partner at Feldmann Nagel Cantafio \& Song PLLC in Denver, Colorado, (303) 2924567, whose practice emphasizes oil and gas law, civil and commercial litigation, natural resources, arbitration and mediation, and commercial transactions; Licensed to practice law in Alaska, Colorado, North Dakota, Texas, Utah, and Wyoming; Lecturer at the Global Energy Management Program at the University of Colorado, Denver; J.D. from University of Colorado School of Law, M.S. in Mineral Economics from Colorado School of Mines, M.S. in Global Energy Management from University of Colorado at Denver, two professional oil and gas certificates in Petroleum Land Management and Energy Finance from University of Denver, B.A. from the University of Nevada, Las Vegas.

${ }^{\dagger}$ Associate at Feldmann Nagel Cantafio \& Song PLLC in Denver, Colorado, (303) 615-2722, whose practice emphasizes oil and gas law, civil and commercial litigation, compliance, and commercial transactions; Licensed to practice law in Colorado; J.D. from University of Denver Sturm College of Law, B.A. and B.S. from Southern Methodist University. 
our country in the immediate and not so distant future: the lack of connectivity between the three interconnects within the United States. Reliable and relatively inexpensive energy is essential to our country's economic health, successfully addressing environmental concerns, and bolstering national security. While many laypersons never stop to consider where energy comes from or how it is delivered, the energy grids in the United States are vitally important to our daily lives. Many concerns have arisen in the last few decades about its efficacy, including most recently in popular culture due to the February 2021 winter storm in the Southern United States that left millions throughout the region, including specifically in Texas and Mississippi, without power for days, and in some cases, weeks.

The issue of delivering electricity has become more acute in the last several years, including reservations as to the safety and security of our energy grid system itself. Beyond these concerns, the energy grid system is widely and generally considered outdated in terms of technology and function.

Functionally speaking, the United States has three separate energy grids: Western Interconnection, the Eastern Interconnection, and the Texas Interconnection. The three grids have very few ties between them and exchange very limited amounts of electricity. This is, as we shall see, a problem that requires a solution.

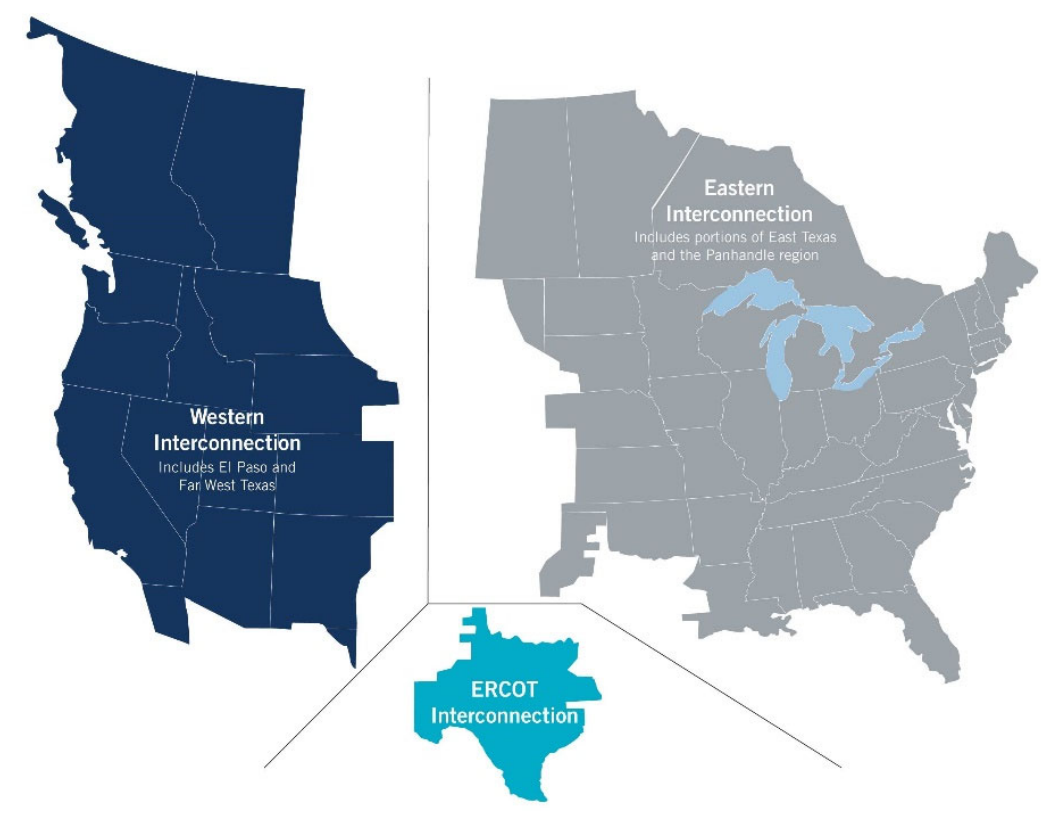


To date, the electrical industry and political response have been sparse. Electric utilities began prioritizing the integrating of operations with greater urgency beginning in the early part of the 20th century by creating additional generating capacity, building up energy reserves, and operating more reliably by sharing energy between generating plants within the same state or region. ${ }^{2}$ Consistent with general notions of wise finance - diversification is important. After World War II, the construction of high-voltage transmission lines allowed the transfer of electricity over greater distances. This, in turn, reduced costs and increased reliability. ${ }^{3}$ Since the late 1960 s and with the creation of the North American Electric Reliability Council (now the North American Electric Reliability Corporation) ("NERC"), utility industry participants continued to coordinate on a larger scale to share and reduce costs. This resulted in safer and more reliable energy sharing. Since 2005, the Federal Energy Regulatory Council ("FERC") has enforced NERC reliability standards throughout the country. ${ }^{4}$

As the country's reliance on oil and traditional nonrenewable resources, such as coal, as a source of energy continues to decline, natural gas and renewable energy options such as wind and solar are becoming more important, even if renewables currently account for only a limited amount of the nation's energy supply of approximately $15 \% .^{5}$ With the increasing demand for electricity now and in the foreseeable future, the potential for rising energy costs burdens every American. This is particularly so in those regions of the United States without access to an abundance of an adequate blend of both renewable and non-renewable energy delivering sources. Further, as climate change continues, natural disasters and other weather events will predictably become more extreme. This, as we can see from the

\footnotetext{
1. Maps, ERCOT, http://www.ercot.com/news/mediakit/maps [https://perma.cc/X3QQ-8K9Y]

2. Jonathan Lesser, America's Electricity Grid: Outdated or Underrated?, THE HERITAGE FOUND. (Oct. 23, 2014), https://www.heritage.org/environment/report/americas-electricity-grid-outdated-orunderrated [https://perma.cc/ZCY7-FCQG].

3. $I d$.

4. Id.

5. Short-Term Energy Outlook, U.S. EnERGY InFO. AdMIN. (Oct. 6, 2020), https://www.eia.gov/outlooks/steo/report/electricity.php\#: :text= Coal's\%20forecast $\% 20$ share $\% 20$ of $\% 20$ electricity,and $\% 20$ to $\% 2022 \% 25 \% 20 \mathrm{in} \% 2$ 02021 [https://perma.cc/K2EW-8QPH].
} 
fires in the Western United States noted in the late summer and autumn of 2020 and the winter storm in the Southern United States in February 2021 , presents an additional risk to our country's energy systemsnot to mention the threat that more extreme temperatures will test both the energy transmission system itself and the pocketbooks of consumers subject to such extremes.

This Article makes the case for a national energy grid so as to better align the source of electrical power with the location of its demands. While this Article is by no means an attempt to present a comprehensive history lesson or technical treatise on the topic, this suggestion takes into account a variety of concerns articulated by both political parties; attempts to suggest alternatives to provide both cleaner and cheaper energy for consumers; accounts for environmental concerns; and believes these suggestions can provide larger profits for energy companies. This Article means to bring about discussion by focusing upon the need for private citizens, politicians, and all industry and environmentalists to address the growing concerns applicable to energy use and consumption in the United States in this seminal time in our history.

\section{ENERGY GRIDS IN THE UNITED STATES}

Functionally, the United States has three main energy grids: the Western Interconnection, the Eastern Interconnection, and the Texas Interconnection. Part of what makes the current intercontinental system obsolete is the disconnect between the location of our nation's population centers and their geopolitical distribution vis-à-vis the location of renewable energy sources, such as natural gas and wind. These non-renewable sources are primarily, although not exclusively, located in the regions covered by both the Western and Texas Interconnections. By way of just a single example, Texas is home to roughly $23 \%$ of the natural gas reserves in the United States. ${ }^{6}$ At the same time, Texas produces the most wind power of any state. ${ }^{7}$ Yet, the State of Texas comprises only a small percentage of the United

6. G. Sanders, A Look at Natural Gas Production in Texas, NPR: STATE IMPACT (July 28, 2011, 8:50 PM), https://stateimpact.npr.org/texas/tag/natural-gasproduction-in-texas/ [https://perma.cc/4ZST-ZMFN].

7. Allen McFarland, Four states account for more than half of U.S. wind electricity generation, U.S. ENERGY INFO. ADMIN. (June 7, 2019), https://www.eia.gov/todayinenergy/detail.php?id=39772 [https://perma.cc/X5BVRR3M]. 
States population-between $8 \%$ and $9 \%$ of the country's total population. ${ }^{8}$

At their heart, the three energy grids each work in roughly the same fashion. We begin with what is admittedly an overly simplistic overview of the electric industry. Energy is generated at power plants. The source of electricity depends on the plant in question and region. This source of energy can be oil, natural gas, coal, solar, or wind, among others. Next, the electricity produced is transferred into transmission lines. The transmission lines carry the electricity to various, local points of distribution where transformers lower their voltage. Transformers, usually located on power poles, further lower voltage before the electricity is distributed to end users. The consumption of electricity is regulated and tracked generally by meters, which we are all too familiar with.

Because each Interconnection primarily distributes electricity from the region it is located in, natural gas or wind energy production in Texas, for example, typically only benefits the Texas Interconnection, which in turn primarily serves Texas utilities and Texas consumers. The same can be said for hydroelectric plants in the Northwest or coalfired plants in the mid-Atlantic region. Such production typically only benefits that respective Interconnection as well as the utilities and consumers within that specific Interconnection. Having explained the interconnected system in the most general fashion, a word as to each interconnection makes sense.

\section{A. Western Interconnection}

The Western Interconnection includes the entirety of Washington, Oregon, California, Idaho, Nevada, Utah, Arizona, and Wyoming. It also includes the majority of Montana, Colorado, and New Mexico and small portions of South Dakota, Nebraska, and Texas (mainly the El Paso area). ${ }^{9}$ According to data provided by the Western Electricity Coordinating Council ("WECC") ${ }^{10}$ addressing the electricity supplied within the Western Interconnection in 2018, the energy supply consisted of:

\footnotetext{
8. Texas Quick Facts, United STATES Census Bureau, https://www.census.gov/quickfacts/fact/table/TX,US/PST045219 [https://perma.cc/9YXX-8H4U].

9. State of the Interconnection, WECC, https://www.wecc.org/epubs/StateOfTheInterconnection/Pages/Capacity.aspx [https://perma.cc/V86D-4TBT].

10. Id.
} 
- $38.2 \%$ natural gas;

- $27.4 \%$ hydroelectric;

- $13.1 \%$ coal;

- $8.5 \%$ wind;

- $6.6 \%$ solar;

- $3.1 \%$ nuclear; and

- $3.1 \%$ other.

Historically, federally owned hydroelectric plants located in the Western Interconnection sell a large quantity of energy to local utilities in the region. ${ }^{11}$ Solar and wind are the fastest growing sources of energy in the Western Interconnection over the last decade. ${ }^{12}$ As with the Eastern Interconnect, the Western Interconnect serves Canada as well.

\section{B. Eastern Interconnection}

The Eastern Interconnection includes states east of the Mississippi River, as well as the entirety of Minnesota, Iowa, Missouri, Arkansas, Louisiana, North Dakota, Kansas, and Oklahoma. It also includes the majority of Nebraska and South Dakota. Additionally, the Eastern Interconnection includes parts of the Texas panhandle and eastern Texas. ${ }^{13}$ The Eastern Interconnection is the largest grid in the United States and accordingly consumes the most energy. ${ }^{14}$ This portends the challenge of moving renewable energies derived from the Western and Texas Interconnection to the Eastern Interconnection. According to data provided by the Department of Energy, ${ }^{15}$ in the eastern states energy use in 2015 consisted of:

- $36 \%$ natural gas;

- $29 \%$ nuclear;

- $28 \%$ coal;

- $3 \%$ hydroelectric; and

- $4 \%$ other.

11. Lesser, supra note 2.

12. State of the Interconnection, supra note 9.

13. U.S. Electric System is Made Up of Interconnections and Balancing Authorities, U.S. ENERGY INFO. ADMIN. (July 20, 2016), https://www.eia.gov/todayinenergy/detail.php?id=27152 [https://perma.cc/3TGKCLFM].

14. Id.

15. East Coast Region Energy Sector Risk Profile, U.S. DEP'T OF ENERGY, https://www.energy.gov/sites/prod/files/2015/10/f27/Energy_Sector_Risk_Profile_ EastCoastRegion.pdf [https://perma.cc/M3ND-3SSU]. 
It is clear that nuclear and coal generated energy, as opposed to that observed in the Western Interconnection and the Texas Interconnection, are significantly more important to the Eastern Interconnection as a whole. Additionally, the Eastern Interconnection observes the highest energy prices within the continental United States due to, at least in part, its location vis-à-vis the location of its energy sources (other than coal) as well as the older age and lesser efficiency of its power plants as compared to the other areas of the United States. ${ }^{16}$

\section{Texas Interconnection}

The Texas Interconnection includes, unsurprisingly, the majority of Texas including major cities, such as Dallas, Fort Worth, Houston, Austin, and San Antonio as well as the Permian Basin region. ${ }^{17}$ According to data provided by the Electric Reliability Council of Texas ("ERCOT"), ${ }^{18}$ the 2019 energy consumption within the Texas Interconnection consisted of:

- $47 \%$ natural gas;

- $20 \%$ wind;

- $20 \%$ coal;

- $11 \%$ nuclear; and

- $2 \%$ other.

The 2020 generating capacity consisted of nearly $52.8 \%$ natural gas, $23.3 \%$ wind, $14.5 \%$ coal, $5.1 \%$ nuclear, $2.2 \%$ solar, and $2 \%$ other. $^{19}$ Over the past few years, natural gas, wind, solar, and alternative energy have continued to grow in terms of energy production and use in Texas.

\section{A SHORT HISTORY}

While the resulting structure might appear illogical, it is a product of the history of the electrical grid itself. Electricity was initially found to evolve in urban areas. In fact, the development of rural electrification did not become even a minor priority until the 1930s as a result of the Great Depression and the New Deal. The initial governmental focus as to electricity production was on that of

16. Lesser, supra note 2 .

17. See Fact Sheet, The Electric Reliability Council of Tex. (Feb. 2020), http://www.ercot.com/content/wcm/lists/197391/ERCOT_Fact_Sheet_2.6.20.pdf [https://perma.cc/6YQD-22GA].

18. Id.

19. Id. 
reliability and cost. Electricity was treated as a matter of local, not national, concern. This was especially so when it came to siting a vast array of electrical facilities and regulating cost. The need to physically move electricity long distances over high-tension transmission lines is a uniquely modern phenomenon. Up until the last several decades, the focus of the electrical grid was much more the optional localizing of power plants vis-à-vis the transportation of energy sources, primarily coal. Moving vast quantities of electricity from remote areas in the west, where renewable sources are much more plentiful, to the east was simply not a priority.

\section{UTILITIES WITHIN THE UNITED STATES}

While regulation of the electrical sector, at least on the business-toconsumer level, has long been the responsibility of the individual states, the federal government recently imposed a number of mandates as it relates to the energy sources used to generate electricity and making available subsidies to affect the cost of switching to renewable energy sources. ${ }^{20}$ In July 2020, the FERC finalized significant reforms to the Public Utility Regulatory Policies Act of 1978 ("PURPA"). These reforms intended to reduce the country's dependence on fossil fuels by encouraging the development of alternative energy generation facilities. ${ }^{21}$

Independently, states continued to develop their own policies, including renewable energy mandates. Such renewable energy standards require utility companies to source a certain minimum amount of the electricity they generate and ultimately sell attributable to renewable energy sources. ${ }^{22}$

Generally speaking, these renewable energy standards are designed to increase over time. ${ }^{23}$ At the time this Article was written, only Alaska, Alabama, Arkansas, Georgia, Idaho, Kentucky, Louisiana, Mississippi, Nebraska, Tennessee, West Virginia, and Wyoming have not established renewable energy standards or objectives. ${ }^{24}$ As more states increase renewable energy requirements, utilities in those states will increasingly need to avail themselves to the ability to comply. It

20. Lesser, supra note 2 .

21. 18 C.F.R. Pt. 292, 375 (2020).

22. Renewable Energy Standards, SOLAR ENERGy INDUSTRIES ASS'N, https://www.seia.org/initiatives/renewable-energy-standards

[https://perma.cc/76RG-AJZ4] (last visited Oct. 15, 2020).

23. $I d$.

24. Id. 
is here that the failure of the three interconnects to allow the flow of electricity outside a given interconnect is a problem. This is a result of the realities of where renewable energy is sourced versus the population centers that will need to be supplied.

For example, an energy utility in Mississippi, where nearly threequarters of total electricity in the state is derived from natural gas, ${ }^{25}$ might (and probably will) eventually have to abide by renewable energy mandates, standards, or goals established by state or federal government. As of now, Mississippi utilities as a member of the Eastern Interconnect cannot easily or economically access electricity from either the Texas or Western Interconnections - it must instead source its electricity from the eastern United States. This result is due to the way in which the modern Interconnection system is aligned and oriented. This structure leaves an unwelcome conundrum for utilities in Mississippi. To meet a renewable mandate, a given utility might have no other choice but to source renewable energy at elevated prices due to a lack of supply in the eastern United States, if they can source renewable energy at all. The incurred costs to meet renewable mandates are not likely to be borne by state or federal governments or even by the utilities themselves. These costs will undoubtedly pass on to consumers, perpetuating a vicious cycle of rising energy costs in already high-use energy states. Mississippi is not at fault, as the state does not have the geography to harness wind and solar energy like Texas or Wyoming. Issues like this will only become more prevalent unless those utilities can access abundant renewal energy sources from outside of their Interconnection.

\section{Public BENEFIT}

Beyond these more practical concerns, studies have supported the contention that investment in a better energy grid would benefit consumers. In 2011, the Electric Power Research Institute ("EPRI") published a report on the cost and benefits to consumers based on the implementation of a "Smart Grid". This would replace traditional wiring with "smart" wires to better inform utilities about consumer demand and the status of the transmission systems. ${ }^{26}$ As part of its

25. Mississippi State Energy Profile, ENERGy InFORMATION AdMINISTRATION (last visited Oct. 15, 2020), https://www.eia.gov/state/?sid=MS [https://perma.cc/FK9Y-ZEMX].

26. C. Gellings, Estimating the Costs and Benefits of the Smart Grid: A Preliminary Estimate of the Investment Requirements and the Resultant Benefits of a Fully Functioning Smart Grid, ELECTRIC POWER RES. INSTITUTE (Mar. 29, 2011), 
(albeit speculative) conclusions, the report suggested that consumers would benefit by a ratio of approximately four to one. More specifically, consumers would benefit between $\$ 1,294$ billion and $\$ 2,028$ billion based on investment between $\$ 338$ billion and $\$ 476$ billion. ${ }^{27}$ Additionally, with each passing year, the cost of the technology underlying these estimates will continue to decrease thanks primarily to improvements in the underlying technology, making this type of investment even more cost-effective over time.

A robust national energy grid, admittedly a system with its own risks and drawbacks-including, for one, cost-which are far too detailed and nuanced to address in full here, could effectively and simultaneously reduce costs for consumers, allow energy utilities to meet mandates or other requirements for renewable use, strengthen our country's commitment in responding to environmental pressures, and likely bring high-paying and high-skilled jobs to numerous urban and rural economies (in terms of re-constructing and re-tooling the Interconnections). This could provide a boom for local, regional, and national concerns providing employment as to domestic service and technology firms, that would be vital participants to the solution.

\section{WHAT IS HOLDING US BACK?}

The need for change is largely stifled by entrenched interests of energy companies and the states in each Interconnection region. For example, it comes as no surprise that ERCOT wants to maintain its status having no interest in federal supervision of the Texas Interconnect. ${ }^{28}$ Texas energy is vitally important to the energy industry of the United States. This is as true today as it has been historically and as it will be in the future. It is predicted that a national energy grid would remedy parochial concerns by providing an incentive to energy companies and utilities to "give a little" but "get a lot." In Northern Europe, for example, inter-country Interconnections provide power to Denmark, Germany, Norway, and Sweden. Denmark's investment into windfarm installations throughout the twenty-first century benefitted not only itself, but also created an energy surplus that the country has sold to Germany, Norway, and Sweden. ${ }^{29}$ These

https://www.epri.com/research/products/1022519 [https://perma.cc/JZ3X-GRR6].

27. Id.

28. Kate Galbraith, Texplainer: Why Does Texas Have Its Own Power Grid?, TEX. TRIB. (Feb. 8, 2011), https://www.texastribune.org/2011/02/08/texplainerwhy-does-texas-have-its-own-power-grid/ [https://perma.cc/T4LM-3TU6].

29. Arthur Neslen, Wind power generates $140 \%$ of Denmark's electricity 
interrelationships amongst and between otherwise separate interconnectivities must be nurtured and supported.

For many years, Texas has led the United States in wind energy, investing billions of dollars into wind energy related infrastructure since the early 2000s. As stated above, Texas generates nearly onequarter of its energy through wind. As the wind industry continues to grow, investment continues to grow as well. Machinery and technology also becomes less expensive (not only in Texas but in many western states as well) and more efficient. This supply of wind related electricity should only continue to grow. The same can be said for other states and other renewables.

This is not to suggest that anyone should abandon the oil and natural gas industries - the industries that are significantly responsible for the growth of the Lone Star State. Even for those individuals or companies who do not want, or do not foresee, a shift into the production of electricity from these nonrenewable resources, would certain states (Texas, for example) not benefit from the ability to sell excess energy to electrical producers located in other states and Interconnections? Selling energy would provide Texas energy companies the opportunity for a greater profit by opening additional energy markets in other Interconnections. In theory, this could simultaneously provide lower electricity prices to Texas consumers, benefit the political and economic interests of the state, and bolster clean, renewable energy systems.

It merits mention that the equipment currently used at the connection points of the various Interconnection systems are, in many cases, nearly four decades old or older. Thus, these are likely near the end of their useful life. ${ }^{30}$ New technology could replace these antiquated systems while providing the infrastructure to transfer energy between the Interconnection systems. Renewable energy is unlike coal or natural gas where the resources to generate electricity is itself transported. With renewable energy, it is the electricity itself that must be moved. Wyoming coal can be transported anywhere in the world. Wind or solar energy generated in Wyoming must instead be

demand, THE GUARDIAN (Jul. https://www.theguardian.com/environment/2015/jul/10/denmark-wind-windfarmpower-exceed-electricity-demand [https://perma.cc/82PT-MH9K].

30. David C. Wagman, It's Time to Tie the U.S. Electric Grid Together, Says NREL Study, IEEE SPECTRUM (Aug. 08, 2018, 6:52 PM), https://spectrum.ieee.org/energywise/energy/the-smarter-grid/after-almost-100years-of-talk-time-might-be-right-to-strengthen-the-interconnect [https://perma.cc/NHK5-WP4S]. 
transferred as electricity from the source. It is the electricity that needs be transferred, not the fuel used to create the energy.

While relevant industry participants would bear the cost of such technology, the return on investment as predicted in this Article should provide a large incentive for whomever makes the admittedly large investment. This Article does not even begin to explore the role of government loan programs, tax incentives, and the like.

Further, either a larger national grid or even multiple grids that are connected in some form or fashion to allow seamless energy sharing would likely improve efficiency and better balance the supply and demand of the growing, nonrenewable electricity created throughout the nation ${ }^{31}$ instead of sequestering the same just in one region (or in the Texas Interconnection's case, one state). This diversity becomes ever more important as we become subject to greater weather impacts and temperature fluctuations inevitably threatening reliability. The Interconnections Seam Study (a partnership including the National Renewable Energy Laboratory, numerous national laboratories, and various academic and industry partners, as part of the Department of Energy's Grid Modernization Initiative) conducted research into these very outcomes. As part of its conclusions, the study found that substantial value exists in increasing the electricity transfer capability between the Interconnections. Transmission of electricity between the Interconnections has a substantial, positive economic impact on the energy developed in each region. Such increased transmission between Interconnections likely results in both increased energy supply and increased opportunity for operating reserve sharing. ${ }^{32}$

\section{CONCLUSION}

The purpose of this Article is to not provide any significant analysis of the wide breath of issues that exist in the delivering of electricity in the United States in upcoming years. The space permitted here does not allow the same. Instead, the goal of this Article is to raise awareness and assist a wide breath of energy professionals in beginning to discuss and examine possible solutions to replace the current Interconnection system. The replacement system should simultaneously benefit the economies each state and the United States as a whole; continue producing reliable and affordable electricity to

31. Interconnections Seam Study, NATIONAL RENEWABLE ENERGY LABORATORY (Oct. 15, 2020), https://www.nrel.gov/analysis/seams.html [https://perma.cc/WY9A-4EW7].

32. Id. 
consumers and industry; increase profitability for the electrical industry participants; reduce the impact on the electrical industry on climate change; make sure electricity remains affordable to consumers; and increase domestic reliance while reducing foreign dependence on energy. 